\title{
Contemplação estética e alienação: A apropriação da estética de Schopenhauer pelos mecanismos da Indústria Cultural
}

\author{
Aesthetic Contemplation and Alienation: \\ The appropriation of Schopenhauer's aesthetics by the mechanisms of \\ Cultural Industry \\ Francisco Fianco \\ Doutor em Estética e Filosofia da Arte pela UFMG \\ Professor do Programa de Pós-Graduação em Letras da UPF/RS \\ E-mail: fcofianco@upf.br
}

\begin{abstract}
Resumo: Nosso texto tem como tema a apropriação de categorias do pensamento de Schopenhauer pelo mecanismo da Indústria Cultural, conforme este foi teorizado por Adorno e Horkheimer. Pressupõe-se a possibilidade de fazer a devida relação argumentativa entre, principalmente, o Livro III de $O$ mundo como vontade e representação e o capítulo sobre a Indústria Cultural da obra Dialética do Esclarecimento. Teremos como objetivo, em um primeiro momento, demonstrar de que maneira o conceito schopenhaueriano de contemplação estética permite, através da anulação da vontade, a anulação do sofrimento inerente à existência para, em um segundo momento, analisar de que modo este mesmo mecanismo, cooptado pela indústria da cultura e pelos meios de comunicação de massa, proporciona um entorpecimento cotidiano resultante em alienação da consciência.
\end{abstract}

Palavras-chave: Contemplação estética; Alienação; Schopenhauer; Indústria Cultural.

Abstract: Our paper has as subject the appropriation of categories from Schopenhauer's thought by the mechanism of Culture Industry as it has been theorized by Adorno and Horkheimer. It assumes the possibility of making the proper relationship between both argumentations, especially, within the third part of The World as Will and Representation and the Culture Industry chapter on the work Dialectic of Enlightenment. We aimed, at first, to demonstrate how the concept of aesthetic contemplation allows Schopenhauer, by canceling the will, the annulment of the suffering inherent at the existence to, in a second moment, consider how this same mechanism, co-opted by the culture industry and the mass media, provides a numbing routine resulting in alienation of consciousness.

Key-words: Aesthetic contemplation; Alienation; Schopenhauer; Culture Industry.

\section{Introdução}

presente texto tem como tema a apropriação de categorias do
pensamento de Schopenhauer pelo mecanismo da Indústria Cultural
conforme este foi teorizado por Adorno e Horkheimer. Pressupõe-se a possibilidade de fazer a devida relação argumentativa entre, principalmente, o Livro III de $O$ mundo como vontade e representação e o capítulo sobre a Indústria Cultural da obra Dialética do Esclarecimento. Teremos como objetivo, em um primeiro momento, demonstrar de que maneira o conceito schopenhaueriano de contemplação estética 
permite, através da anulação da vontade, a anulação do sofrimento inerente à existência enquanto unidade subjetiva para, em um segundo momento, analisar de que modo este mesmo mecanismo, cooptado pela indústria da cultura e pelos meios de comunicação de massa, proporciona um entorpecimento cotidiano resultante em alienação da consciência tanto no sentido de separá-la do mundo quanto de realizar a delegação da autoridade sobre esta consciência aos domínios de uma alteridade sistêmica e manipuladora.

Isso não implica, em momento algum, sugerir que a estética schopenhaueriana tenha em si, mesmo que em germe, os mecanismos de alienação e todas as suas consequências negativas, senão ao contrário, a constatação de como, efetivamente, elementos desta estética foram apropriados explicitamente pela indústria da cultura. Cabe-nos, portanto, em um último esforço, esclarecer as diferenças entre estes modelos de pensamento para poder, inclusive, demonstrar como, de forma inerente ao pensamento de Schopenhauer, se pode encontrar os meios de resistência ao esquematismo totalizante e hegemonizante da Indústria Cultural. Para tanto, iniciaremos tentando pensar a influência da filosofia de Schopenhauer sobre os dois pensadores da Escola de Frankfurt em questão, Theodor Adorno e Max Horkheimer para, em um segundo momento, reconstruir em linhas gerais a argumentação do Livro III de $O$ mundo como vontade e representação, vinculando desejo e sofrimento e sua possibilidade de anulação através da contemplação estética. Num último momento, tentaremos demonstra de que maneira as críticas de Adorno e Horkheimer a respeito da Indústria Cultural no capítulo homônimo de Dialética do Esclarecimento descrevem procedimentos de manipulação intelectual e subjetiva semelhantes àqueles propostos pela contemplação estética schopenhaueriana no intuito de, mais do que encontrar semelhanças, apontar as diferenças entre um modelo e outro, a fim de deixar bem claro o processo de apropriação do veículo de contemplação estética pela indústria da cultura, transformando em alienante aquilo que foi proposto originalmente como uma emancipação da consciência através da arte.

\section{A influência de Schopenhauer na Escola de Frankfurt}

Um dos aspectos mais importantes dos diversos pensadores componentes da assim chamada Escola de Frankfurt é a metodologia de trabalho e pensamento que se percebe em todos eles, ou seja, em oposição à teoria tradicional cartesiana, o recurso à 
Teoria Crítica, formulada magistralmente por Max Horkheimer com a intenção de ser um processo de pensamento que superasse a oposição radical entre sujeito e objeto, pensador e mundo, e que, entre outras coisas, possibilitasse uma transformação do mundo e não apenas uma descrição dele. Portanto, pode parecer contraditório que justamente Horkheimer o cite como, juntamente com Marx, um dos dois filósofos que influenciou diretamente o surgimento da Teoria Crítica em seu texto Teoria crítica ontem e Hoje, de 1969. Isso porque Schopenhauer elaborou, em oposição à Marx, o outro filósofo citado, uma filosofia que não reconhecia a possibilidade de transformação da realidade em algo melhor e que, além desse caráter pessimista, trazia consigo um aspecto radicalmente individualizante e elitista, em oposição ao comprometimento político daquela teoria com a transformação social e política. Porém, apesar disso, em diversos momentos, não apenas nos cinco textos sobre Schopenhauer que escreveu para palestras na Schopenhauer-Gesellchaft de Frankfurt Am Main, da qual fazia parte desde a época de estudante, Horkheimer confessa claramente sua vinculação com o pessimismo metafísico, e com tanta força que nem mesmo o comprometimento político conseguiria desfazê-lo.

O pessimismo metafísico, momento implícito em todo pensamento genuinamente materialista, me foi familiar desde sempre. À obra de Schopenhauer devo meu primeiro contato com a filosofia; a relação com a doutrina de Hegel e de Marx, o desejo de compreender e de mudar a realidade social não resgataram, apesar do contraste político, minha experiência com sua filosofia ${ }^{1}$.

Esse pessimismo inerente a todo o materialismo pode ser entendido como o retorno do passado inexorável e infeliz, pleno de sofrimento, a partir do qual se dá todo o esforço de mudança e o comprometimento social da Teoria Crítica, mesmo que, e isso apenas acentua o pessimismo inerente, o sofrimento do passado nunca possa ser justificado e as vítimas redimidas. Isso coloca em cheque o conceito de racionalidade da filosofia, até então entendido como racionalidade absoluta e que Horkheimer denuncia como racionalidade instrumental, ou seja, uma racionalidade que permita ao sujeito a submissão dos objetos. E precisamente aí temos mais um ponto de convergência entre ambos, pois podemos identificar já em Schopenhauer a crítica nodal a esta noção de racionalidade absoluta entendida em sua argumentação como racionalidade subjetiva,

\footnotetext{
${ }^{1}$ HORKHEIMER, M. Teoria Crítica I, p. 8. 
ou seja, egoísta, intencional, calculativa, vinculada à satisfação dos desejos individuais e, portanto, diretamente implicada no sofrimento que é o mundo, e a racionalidade objetiva, libertadora e desvinculada da vontade de viver, a razão em forma de consciência pura, que inclusive contribui para a anulação do desejo e, com esse, do sofrimento.

Em Adorno, por outro lado, a filosofia de Schopenhauer aparece de forma bastante emblemática em um dos parágrafos de Minima Moralia, o de número 99, no qual o autor faz uma reflexão sobre a decadência da moralidade burguesa após o ocaso dos sistemas religiosos como possibilidades de fundamentação transcendente da moral. Assim, essa ausência de referências externas obriga o sujeito a um mergulho no individualismo, ao mesmo tempo em que o possibilita elevar a sua unidade subjetiva como padrão regulador de comportamento. $\mathrm{O}$ aspecto problemático nesse momento é a possibilidade de que, o que foi largamente desenvolvido pelos filósofos críticos e contemporâneas da burguesia decadente, o próprio conceito de unidade subjetiva seja por si mesma demasiadamente inexata para poder funcionar como fundamentação imanente. É por tal razão que a própria noção de $\mathrm{Eu}$, o próprio conceito de individualidade, vai ser identificado como uma produção abstrata e artificializada pela sociedade de consumo. Não apenas a noção de uma unidade subjetiva está intimamente ligada à sociedade como provém dela mesma em seus aspectos mais íntimos, como a sua origem, que se faz a partir dessa estrutura ou de sua relação constante com o mundo enquanto objeto.

\begin{abstract}
Ninguém o exprimiu com tanta franqueza quanto Schopenhauer. O rabugento avô da filosofia da existência e herdeiro maldoso dos grandes especuladores estava familiarizado como ninguém com as cavernas e desfiladeiros do absolutismo individual. Sua intuição vem juntar-se à tese especulativa de que o indivíduo seria mera manifestação e não coisa em si ${ }^{2}$.
\end{abstract}

Por tal razão, qualquer análise do eu, qualquer abordagem crítica da subjetividade, não pode considerá-lo como uma unidade ontológica, quando muito em um caráter teológico, ou seja, algo que pode ser conhecido mediante intuição imediata, e não através de elaboração conceitual. Em Schopenhauer isso foi perfeitamente tematizado através da possibilidade de conhecer a coisa-em-si não através dos sentidos e

\footnotetext{
2 ADORNO, T. W. Minima Moralia, p. 135. 
Revista Voluntas: Estudos sobre Schopenhauer - Vol. 6, No 1 - $1^{\circ}$ semestre de 2015 - ISSN: 2179-3786 - pp. 102-119.

da razão, que sempre lida com os fenômenos que constituem o mundo como representação do sujeito, e sim pelo contato com a vontade de viver que se objetifica em cada um de nós através do corpo. Mesmo a ínfima noção de "eu" já constitui um resultado da ilusão que a vontade cria em nós para ter-nos como veículo de sua realização, o que explica que sempre a satisfação dos desejos cegos da vontade de viver através da elaboração da nossa racionalidade sejam a causa dos sofrimentos com que os seres humanos se debatem ao longo da vida, e que isso só possa ser amenizado através da contemplação estética, de acordo com os argumentos que seguem.

\section{A contemplação estética como anulação da vontade}

Schopenhauer abre o Livro III de $O$ mundo como vontade e representação, sobre a estética, com uma recapitulação dos seus argumentos anteriores sobre a representação enquanto esquema de percepção do mundo e a vontade como essência da existência, descrevendo sua filosofia como uma unificação da representação do fenômeno conforme a teoria do conhecimento kantiana e a intuição da vontade como apreensão da ideia de acordo com o modelo platônico:

Sendo a vontade a coisa em si, e a ideia a objetividade imediata desta vontade em um grau determinado, atinamos com a coisa em si de Kant e a ideia de Platão, única que lhe é óntôs ón, estes dois grandes obscuros paradoxos dos dois maiores filósofos do Ocidente, não como idênticas, porém como estreitamente afins, e distintas apenas por uma única determinação ${ }^{3}$.

Tal esquema revela a plenipotência cognitiva do sujeito em um primeiro momento, mas tem como consequência a dor e o sofrimento, pois ao mesmo tempo em que o mundo é para o sujeito a sua representação, o próprio sujeito pode ser entendido como uma construção artificial, fruto do logro da vontade que se vale do sujeito para a sua objetivação. Isso quer dizer que a vontade, princípio motor da existência subjetiva, tem como consequência direta a dor e o sofrimento, pois a vontade é sempre de algo que não se tem, fazendo com que a existência oscile desesperadamente entre a angústia do desejo, sua realização fugaz, e o tédio subsequente. Em outras palavras, a existência é dor e sofrimento incessantes.

\footnotetext{
${ }^{3}$ SCHOPENHAUER, A. MRV III, § 31, p. 12, todos os grifos das citações são do autor. 
Como a essência do homem consiste em que a sua vontade deseja, é satisfeita e deseja novamente, e assim indefinidamente, e como sua felicidade e bem-estar consistem apenas em que a transição do desejo à satisfação, e desta ao novo desejo, prossiga com rapidez uma vez que a ausência da satisfação é sofrimento, e a do novo desejo, ansiedade vazia, languor, tédio ${ }^{4}$;

Dentro desse modelo de pensamento, Schopenhauer coloca a possibilidade de anulação do sofrimento em primeiro lugar através da contemplação estética, através da arte, e essa possibilidade e suas modalidades de realização são os desenvolvimentos argumentativos do terceiro Livro de $O$ mundo como vontade e representação, que trata da representação mediante um segundo ponto de vista, ou seja, o estético, e não mais o gnosiológico, por meio do qual ele foi abordado no primeiro Livro. Assim, se o sofrimento vem do fato de o sujeito estar encerrado em uma individualidade que percebe o mundo de forma subjetiva e isolada, a possibilidade de transcender a essa configuração passa pela plena objetificação, pela contemplação estética capaz de ultrapassar a racionalidade da representação fenomênica racional e subjetiva e que possa despersonalizar o sujeito, tornando-o "olho do mundo", ou seja, pura contemplação, a anulação do sofrimento do sujeito a partir de sua dissolução plena no objeto que ele contempla.

\begin{abstract}
Esta transição possível, porém, sempre excepcional, do conhecimento comum de coisas individuais, ao conhecimento da ideia, ocorre de modo repentino, ao arrancar-se o conhecimento ao serviço da vontade, por cessar precisamente o sujeito de ser meramente individual, tornando-se agora sujeito puro do conhecimento, destituído de vontade, não mais se ocupando, conforme o princípio de razão, das relações; mas repousando e sendo absorvido na contemplação firme do objeto oferecido fora de quaisquer conexões com outros ${ }^{5}$.
\end{abstract}

O processo por meio do qual é possível que se realize essa superação da consciência individual passa pela contemplação estética, ou seja, está diretamente relacionado à capacidade humana de valorização da arte e das experiências sensíveis em relação ao belo. Enquanto as relações cognitivas mantém o sofrimento inerente à

\footnotetext{
${ }^{4}$ SCHOPENHAUER, A. MRV III, § 52, p. 82.

${ }^{5}$ SCHOPENHAUER, A. MRV III, § 34, p. 18.

Contemplação estética e alienação
} 
Revista Voluntas: Estudos sobre Schopenhauer - Vol. 6, No 1 - $1^{\circ}$ semestre de 2015 - ISSN: 2179-3786 - pp. 102-119.

existência entendida como racionalidade individual e consegue apenas compreender as relações quantificáveis entre as coisas existentes, a experiência estética conduz o sujeito diretamente à contemplação da essência das coisas, em forma de um conhecimento intuitivo que passa pela sensibilidade, levando diretamente à contemplação das ideias eternas, à essência das coisas. Reside nisso a capacidade da arte de anular a vontade e o sofrimento, que é mais elevada no gênio do que no homem comum, pois aquele tem a capacidade de "abstrair por completo de seu interesse, seu querer, seus objetivos, despojar-se por um tempo inteiramente de sua personalidade, para permanecer sujeito puro do conhecimento: [...]"6. Isso abre a possibilidade de uma relação com o mundo em duas formas distintas: entende-lo como comumente ele é entendido, de forma que as coisas tenham validade em função de sua relação recíproca, de modo a sempre diferenciar-se entre sujeito conhecedor e objetos conhecidos, sedimentando esta relação de desejo e sofrimento, ou intuitiva e esteticamente, em uma fusão do sujeito com o mundo contemplado no qual os limites entre subjetividade e objetividade se anulem, negando o principium individuationis enquanto fonte da ilusão de consciência e do sofrimento do desejo.

Encontramos na contemplação estética dois elementos inseparáveis: o conhecimento do objeto, não como coisa individual, mas como ideia platônica, i. e., forma permanente deste conjunto de coisas; e a consciência de si do sujeito cognoscente, não como indivíduo, mas como sujeito puro, independente da vontade, do conhecimento ${ }^{7}$.

O querer é, portanto, a fonte do sofrimento. O querer, que é expressão da vontade, causa o sofrimento porque o sujeito não compreende que o mundo, enquanto sua representação, é apenas um véu de fenômenos, de modo que deseja coisas que lhe parecem ser a solução de seu sofrimento desejante sem perceber que nessas coisas não é o seu sofrimento que se anula, e sim a vontade cega e inexorável que se realiza e se objetifica através dele, deixando o seu sofrimento, como angústia individual, intacto e perene. Dessa maneira, se entende que a origem do querer seja a necessidade e a carência que, em forma de falta, dão possibilidade ao sofrimento que não cessa com a sua satisfação senão apenas de forma fugidia e tênue, pois o desejo realizado se substitui imediatamente um novo desejo. Esse processo constante faz com que a ilusão presente,

\footnotetext{
${ }^{6}$ SCHOPENHAUER, A. MRV III, § 36, p. 24.

${ }^{7}$ SCHOPENHAUER, A. MRV III, $\S 38$, p. 32.

Contemplação estética e alienação
} 
já conhecida e desencantada, seja sempre substituída pela ilusão desconhecida em forma de satisfação ainda não alcançada, "como a caridade oferecida a um mendigo, a lhe

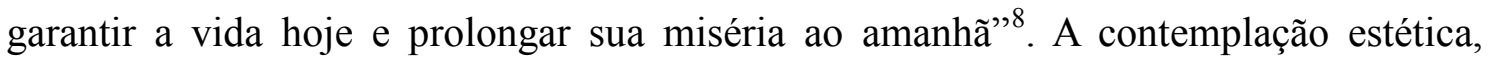
como atitude intelectiva desindividualizante e livre da vontade, aparece como possibilidade de uma relação cognitiva imediata com a essência das coisas, com a idéia. Ao passo que o conceito é racional e mantém a estrutura subjetiva responsável pelo sofrimento de existir, a contemplação é intuitiva e se direciona diretamente a essência da vida, sem os intermediários da racionalidade que circunscreve a subjetividade sofredora.

É justamente por isso que o atormentado pela paixão, ou pela necessidade e preocupação, é tão subitamente aliviado, reconfortado e alegrado por uma única visão livre da natureza; a tormenta das paixões, o impulso do desejo e do temor, e todo o sofrimento do querer são imediatamente apaziguados de um modo maravilhoso. Pois no momento em que, arrancados do querer, nos abandonamos ao conhecimento puro, independente da vontade, penetramos em um outro mundo, em que tudo o que movimenta nossa vontade, e por isto nos abala com tal intensidade, não mais existe. Esta libertação do conhecimento nos subtrai a tudo isso de maneira análoga ao sonho e ao sono: felicidade e infelicidade desapareceram; não somos mais o indivíduo, que está esquecido, mas apenas sujeito puro do conhecimento 9 .

É em função dessas considerações que Schopenhauer faz uma recapitulação erudita e qualificada das artes em suas diversas formas de manifestação, explicando-as de acordo com o nível de objetificação da vontade que apresentam e sua maior capacidade de anulação da consciência subjetiva e, por conseguinte, do sofrimento. Nesse sentido, de certa forma ainda bastante vinculado à estética kantiana, ele coloca no topo de sua hierarquia artística a música, pois nela se conserva em menor grau possível a representatividade conceitual que figura em outras artes, sendo ela a mais propícia a transportar a consciência para lugares distantes da subjetividade de maneira a promover esta anulação temporária do querer. Ou seja, quanto menos representativa, mais abstrata, mais fortemente ela pode propiciar ao sujeito que se desprenda de sua circunstância.

\footnotetext{
${ }^{8}$ SCHOPENHAUER, A. MRV III, $\S 38$, p. 32.

${ }^{9}$ SCHOPENHAUER, A. MRV III, § 38, p. 33.

Contemplação estética e alienação
} 
Ao designarmos uma coisa de bela, exprimimos assim ser ela objeto de nossa observação estética, o que encerra duas explicações: em primeiro lugar, de que sua visão nos torna objetivos, i. e., que nós em sua observação não mais somos conscientes de nós mesmos como indivíduos mas como sujeitos puros do conhecimento independentes da vontade; em segundo lugar, que reconhecemos no objeto não a coisa individual, mas uma ideia, o que se verifica apenas enquanto nossa observação do objeto não se submete ao princípio de razão, sem perseguir uma relação sua com algo que lhe é exterior (que em última instância sempre está ligada a relações com a nossa vontade), repousando sobre o objeto ele próprio ${ }^{10}$.

Esse esquema de anulação da vontade não chega a se configurar como o auge do pensamento schopenhaueriano, pois a esta saída fugidia ele contrapõe a ascese desenvolvida longamente no Livro IV de $O$ mundo como vontade e representação, onde traça suas considerações sobre a moral da compaixão e da anulação da vontade de forma senão permanente pelo menos mais duradoura do que pela contemplação estética através do exercício intelectual e filosófico, aproximando-se bastante do pensamento estoico e integrando à filosofia alemã as constatações do pensamento oriental. Porém, nos deteremos a estas considerações sobre o a importância da arte no seu pensamento como meio de pensarmos as relações possíveis entre estética e ética no contexto nosso contemporâneo, razão pela qual se faz necessário que passemos então à uma recapitulação dos principais elementos da crítica à Industria Cultural conforme ela foi teorizada por Adorno e Horkheimer principalmente no capítulo homônimo dentro da obra Dialética do Esclarecimento.

\section{Alienação através da arte comercial na Indústria Cultural}

Ao longo do terceiro Livro de $O$ mundo como vontade e representação, Schopenhauer, além de descrever a argumentação que retomamos em linhas gerais acima, faz uma análise filosófica das diversas modalidades de representação estética de acordo com os conceitos de sua filosofia, declarando a música como a mais elevada das artes pelo fato de ser a menos representativa, ou seja, a mais apta a elevar o sujeito à contemplação imediata da ideia que ela, a arte, representa. No novo contexto que estamos trazendo, então, à nossa discussão, o da Indústria Cultural, uma das primeiras possibilidades de valorização da arte como meio de conhecimento é anulada, ou seja,

\footnotetext{
${ }^{10}$ SCHOPENHAUER, A. MRV III, § 41, p. 42.

Contemplação estética e alienação
} 
esboroam-se os limites entre as diversas formas de arte, de forma a permitir que todas as suas manifestações sirvam então a uma intencionalidade universal, mais nociva, então, à experiência estética emancipatória do que a representatividade que impossibilitava a contemplação desinteressada.

\begin{abstract}
Emancipando-se, o detalhe tornara-se rebelde e, do romantismo ao expressionismo, afirmara-se como expressão indômita, como veículo do protesto contra a organização. O efeito harmônico isolado havia obliterado, na música, a consciência do todo formal; a cor particular na pintura, a composição pictórica; a composição psicológica no romance, a arquitetura. A tudo isso deu fim a indústria cultural mediante a totalidade. Embora nada mais conheça além dos efeitos, ela vence a sua insubordinação, e os submete à fórmula que substitui a obra. Ela atinge igualmente o todo e a parte ${ }^{11}$.
\end{abstract}

Todas as artes das quais fala Schopenhauer se encerram na totalidade que lembra o espírito absoluto que ele tanto negava. Isso desmente, de certa forma, a ideia ingênua de que o mundo moderno esteja vazio de significado, que a arte não tenha mais o que que representar em termos de ideias universais, e é justamente com esta reflexão que Adorno e Horkheimer abrem o capítulo sobra a Industria Cultural de se livro Dialética do Esclarecimento.

Na opinião dos sociólogos, a perda de apoio que a religião objetiva fornecia, a dissolução dos últimos resíduos pré-capitalistas, a diferenciação técnica e social e a extrema especialização levaram a um caos cultural. Ora, essa opinião encontra cada dia um novo desmentido. Pois a cultura contemporânea confere a tudo um ar de semelhança. O cinema, o rádio e as revistas constituem um sistema. Cada setor é coerente em si mesmo e todos o são em conjunto ${ }^{12}$.

Em outras palavras, muito longe de termos um mundo vazio no qual as pessoas pudessem passar pela experiência libertadora de se sentirem perdidas, tem-se um esquematismo e um planejamento que levam em consideração cada ínfimo aspecto da vida cotidiana, elucidando que o desconforto contemporâneo não é a ausência de determinações, e sim a determinação absoluta da identificação do indivíduo com o todo operada através dos meios de comunicação em massa. Isso perpassa aspetos mais

\footnotetext{
${ }^{11}$ ADORNO; T. W.; HORKHEIMER, M. Dialética do Esclarecimento, p. 104.

${ }^{12}$ ADORNO; T. W.; HORKHEIMER, M. Dialética do Esclarecimento, p. 99. 
Revista Voluntas: Estudos sobre Schopenhauer - Vol. 6, No 1 - $1^{\circ}$ semestre de 2015 - ISSN: 2179-3786 - pp. 102-119.

diversos da subjetividade contemporânea, inclusive a sua própria possibilidade de formação em termos psicológicos. Porém, como aqui o que mais nos interessa são as relações dessa subjetividade com seu lazer através do consumo de mercadorias culturais, devemos chamar a atenção para o fato de que aquilo que anteriormente era uma produção individual, ou seja, a constituição da própria personalidade, agora fica ao encargo dos meios de comunicação de massa.

Em seu lazer, as pessoas devem se orientar por essa unidade que caracteriza a produção. A função que o esquematismo kantiano ainda atribuía ao sujeito, a saber, referir de antemão a multiplicidade sensível aos conceitos fundamentais, é tomada ao sujeito pela indústria. $\mathrm{O}$ esquematismo é o primeiro serviço prestado por ela ao cliente $^{13}$.

O fato de que esse processo se dê por meio dos momentos de lazer apenas denuncia mais radicalmente a perversidade deste processo, pois esse lazer, que é entendido apenas como tempo de descanso entre um turno produtivo e outro, se converte em submissão intelectual e assimilação às tendências totalitárias do universal.

Ao subordinar da mesma maneira todos os setores da produção espiritual a este fim único - ocupar os sentidos dos homens à saída da fábrica, à noitinha, até a chegada ao relógio do ponto, na manhã seguinte, com o selo da tarefa de que devem se ocupar durante o dia essa subsunção realiza ironicamente o conceito da cultura unitária que os filósofos da personalidade opunham à massificação ${ }^{14}$.

Através da eficiência da sugestão possibilitada pelo estado de "atenção desatenta", a publicidade pode seguir criando desejos embutidos subliminarmente nas produções culturais que, pérfida e ironicamente, sustentam o rótulo de "apenas divertir", transformando em escárnio sobre a capacidade crítica de seus espectadores o bordão Ars Gratia Artis.

Mas a afinidade original entre os negócios e a diversão mostra-se em seu próprio sentido: a apologia da sociedade. Divertir-se significa estar de acordo. Isso só é possível se isso se isola do processo social em seu todo, se idiotiza e abandona desde o início a pretensão

${ }^{13}$ ADORNO; T. W.; HORKHEIMER, M. Dialética do Esclarecimento, p. 103.

${ }^{14}$ ADORNO; T. W.; HORKHEIMER, M. Dialética do Esclarecimento, p. 108.

Contemplação estética e alienação 


\section{FRANCISCO FIANCO}

inescapável de toda obra, mesmo da mais insignificante, de refletir em sua limitação o todo. Divertir significa sempre: não ter que pensar nisso, esquecer o sofrimento até mesmo onde ele é mostrado. A impotência é sua própria base. É na verdade uma fuga, mas não, como afirma, uma fuga da realidade ruim, mas da última idéia de resistência que essa realidade ainda deixa subsistir. A liberação prometida pela diversão é a liberação do pensamento como negação ${ }^{15}$.

Dois momentos podem ser depreendidos a partir da citação anterior. O primeiro é o da distração; e o segundo o da eliminação da oposição, eliminação da consciência que é consequentemente eliminação da capacidade crítica. No primeiro, tem-se o mecanismo de eficiência da construção da subjetivação a partir da distração, de todas as técnicas subliminares de levar os espectadores a posicionarem-se de acordo com aquilo que os transmissores entendem por mais adequado aos seus fins, elencando aí não apenas a ideologia por trás das produções culturais como mesmo a manipulação da informação transmitida de forma direta. O segundo, consequência deste primeiro, é a eliminação da oposição crítica, e esvaziamento das consciências, a coisificação dos sujeitos.

Quanto menos promessas a indústria cultural tem a fazer, quanto menos ela consegue dar uma explicação da vida como algo dotado de sentido, mais vazia torna-se necessariamente a ideologia que ela difunde. Mesmo os ideais abstratos da harmonia e da bondade da sociedade são demasiado concretos na era da propaganda universal. Pois as abstrações são justamente o que aprendemos a identificar como propaganda. A linguagem que apela apenas à verdade desperta tão somente a impaciência de chegar logo ao objetivo comercial que ela na realidade persegue ${ }^{16}$.

Falando bem claramente: o filme adestra. Uma ideia mais antiga dentre os pensadores da Escola de Frankfurt é a de que da mesma maneira que a humanidade interfere na produção de tecnologia, a tecnologia disponível transforma a humanidade. ${ }^{17}$ $\mathrm{Ou}$, dito de forma mais clara, da mesma maneira que os cineastas modificam as técnicas de cinema, estas linguagens filmográficas transformam as capacidades perceptivas dos sujeitos, talvez até mesmo alterando ou modelando e remodelando o esquematismo

\footnotetext{
${ }^{15}$ ADORNO; T. W.; HORKHEIMER, M. Dialética do Esclarecimento, p. 119.

16 ADORNO; T. W.; HORKHEIMER, M. Dialética do Esclarecimento, p. 121.

17 BENJAMIN, W. A obra de arte na era de sua reprodutibilidade técnica, In: Arte e Política, 165 - 196. Magia e Técnica, 
perceptivo kantiano dentro do qual podemos entender o mundo como representação mediatizada do sujeito. Nesse sentido, temos uma incontestável influência da celeridade cinematográfica sobre a capacidade de reflexividade subjetiva e, principalmente, do tempo de atenção. Assim, o que o a Indústria da Cultura realiza é o aumento daquela celeridade que Schopenhauer já identificava na trajetória incessante que vai do desejo/satisfação/tédio ao novo desejo, com suas imediatas consequências ao processo de contemplação estética, o qual poderia fazer cessar esse círculo de sofrimento.

O homem comum, este produto industrial da natureza, tal como esta o apresenta diariamente aos milhares, é incapaz, ao menos de modo persistente, de uma observação em todo sentido inteiramente desinteressada: ele pode dirigir sua atenção às coisas somente enquanto estas apresentam uma relação qualquer, mesmo que apenas mui mediatizada, com a sua vontade. [...] o homem comum não permanece muito tempo com a pura intuição, não fixando por muito tempo sua visão num objeto, mas procura em tudo o que se lhe apresenta apenas rapidamente o conceito sob o qual o alojar, assim como o indolente procura a cadeira, após o que isso já não lhe interessa. Por isso ele esgota tudo com rapidez, obras de arte, objetos belos da natureza, a visão propriamente sempre significativa da vida em todos os seus atos ${ }^{18}$.

Então, por um lado, temos a constatação da produção massificada das subjetividades que, se em Schopenhauer aparece como resultado da natureza, ou como objetificação da vontade, no contexto frankfurtiano será consequência da submissão dos meios de comunicação aos meios de produção, criando uma homogenia tanto dos diversos setores da sociedade quanto das subjetividades individuais que a compõe.

A pseudo-individualidade é o pressuposto para compreender e tirar da tragédia sua virulência: é só porque os indivíduos não são mais indivíduos, mas sim meras encruzilhadas das tendências do universal, que é possível reintegrá-los totalmente na universalidade ${ }^{19}$.

Por outro lado, temos a relação instrumental dos sujeitos com o mundo e com os demais sujeitos, ou seja, a incapacidade de uma contemplação estética emancipatória, de acordo com os argumentos de Schopenhauer, uma vez que a sociedade como um todo esteja sempre pautada pelo modelo de relação interpessoal que se concentra no

\footnotetext{
${ }^{18}$ SCHOPENHAUER, A. MRV III, § 36, p. 25.

${ }^{19}$ ADORNO; T. W.; HORKHEIMER, M. Dialética do Esclarecimento, p. 128. 
estabelecimento de relações quantitativas entre as coisas em um mundo no qual até mesmo os sujeitos são reificados. Isso faz com que, ao contrário de apaziguar os desejos através da contemplação estética, esta contemplação seja usada para instrumentalizar os desejos, para transformar a sua promessa de realização em uma fonte inesgotável de desejos e mais desejos que são sempre demonstrados como apenas possibilidade, como promessa de plenitude que nunca deve se realizar, pois, uma vez realizada, perderia sua força de comoção subjetiva.

A indústria cultural não cansa de lograr seus consumidores quanto àquilo que está continuamente a lhe prometer. [...] Eis aí o segredo da sublimação estética: apresentar a satisfação como uma promessa interrompida. A indústria cultural não sublima, mas reprime ${ }^{20}$.

Isso nos remete a outro aspecto demonstrado por Schopenhauer e que foi cooptado pela indústria da cultura, a extrema importância que tem a sexualidade, enquanto objetificação da vontade, na existência dos indivíduos. Como força maior, é justamente ela que deve ser dominada, que deve ser insinuada e redirecionada para o desejo de consumo, de maneira que o sujeito passe a preferir a realização ilusória de seus desejos na representação estética, do que a frustração deles no confronto com a realidade social.

Quem se diverte num tal jogo é um fantasista: facilmente mesclará as imagens, com que se delicia solitariamente, com a realidade, tornando-se, assim, imprestável para esta: talvez lhe ocorra relatar as fraudes de sua fantasia, que se constituirão comumente em romances de todos os tipos, a entreter seus semelhantes e o grande público, ao se imaginarem os leitores no lugar do herói, encontrando assim a representação bem "agradável" 21 .

É nesta utilização da representação para apaziguar desejos frustrados que reside a distinção entre a contemplação estética emancipatória, acessível ao homem de gênio, e a alienação estética da massa. Enquanto estes usam a arte intencionalmente para aplacar de forma medíocre o sofrimento ocasionado pela vontade, tendo um lampejo de beatitude que logo é sobstituído por outro desejo, o gênio abre mão de pensar as

\footnotetext{
${ }^{20}$ ADORNO; T. W.; HORKHEIMER, M. Dialética do Esclarecimento, p. 115.

${ }^{21}$ SCHOPENHAUER, A. MRV III, § 36, p. 25.

Contemplação estética e alienação
} 
Revista Voluntas: Estudos sobre Schopenhauer - Vol. 6, № 1 - $1^{\circ}$ semestre de 2015 - ISSN: 2179-3786 - pp. 102-119.

relações intencionais entre as coisas e os fenômenos, saindo de si mesmo e anulando a vontade na mesma medida em que se objetifica na contemplação do objeto não como fuga, e sim como plenitude, o que é um processo muito maior do que um momento fugidio de anulação da dor de existir.

A relação da contemplação estética com o enfrentamento da vida pode ser entendida, em último caso, como o enfrentamento do trágico através da arte, que Adorno e Horkheimer tematizam na quinta e última parte de seu texto sobre a Indústria Cultural e em sua relação com a categoria do sublime dentro das considerações estéticas desse terceiro Livro de $O$ mundo como vontade e representação. A sociedade totalizante é o governo do universal, da massa, da produção da pseudo-individualidade, e a relação desse sujeito massificado com o trágico fundamenta a relação estética com a existência a partir da categoria do sublime enquanto contemplação não alienante, pois tanto no trágico quanto no sublime, temos um enfrentamento de um indivíduo, no meio de todas as suas fragilidades e contingências, com um contexto que the ultrapassa e que, ao mesmo tempo em que o fascina, ameaça esmagá-lo com a força da necessidade inexorável. E é essa relação com o trágico o que fundamenta a relação estética com o sublime enquanto uma contemplação não alienante, pois o sublime não apazigua, ele provoca, ao mesmo tempo em que anula a individualidade no todo mais amplo e não na identificação projetiva com os objetos como na alienação estimulada pela Indústria Cultural mesmo em sua apropriação dos elementos potencialmente trágicos que serviriam de oposição crítica.

O trágico é reduzido à ameaça da destruição de quem não coopera, ao passo que seu sentido paradoxal consistia outrora à resistência desesperada à ameaça mítica. $\mathrm{O}$ destino trágico converte-se na punição justa, na qual a estética burguesa sempre aspirou a transformá-la. Mesmo o pior dos finais, que tinha outrora um objetivo mais alto, é mais uma confirmação da ordem e uma corrupção do trágico, [...]. O cinema torna-se efetivamente uma instituição de aperfeiçoamento moral. As massas desmoralizadas por uma vida submetida à coerção do sistema, e cujo único sinal de civilização são comportamentos inculcados a força e deixando transparecer sempre sua fúria e rebeldia latentes, devem ser compelidas à ordem pelo espetáculo de uma vida inexorável e da conduta exemplar das pessoas concernidas $^{22}$.

${ }^{22}$ ADORNO; T. W.; HORKHEIMER, M. Dialética do Esclarecimento, p. 126. 


\section{FRANCISCO FIANCO}

A apropriação dos elementos trágicos realizada pela indústria da cultura demonstra sua intencionalidade pedagógica, no sentido de realizar uma heteronomia dos sujeitos, inculcando-lhes, direta ou subliminarmente, padrões de comportamento socialmente aceitável e sugerindo-lhes os desejos de consumo e aspirações pessoais que sejam mais interessantes ao contexto. Dessa forma, o sujeito se identifica com os personagens e com os produtos que lhe são apresentados, realizando sim uma anulação do sofrimento, mas de forma medíocre e alienante, ou seja, buscando estas respostas em representações culturais produzidas intencionalmente como mercadorias. É a contemplação do belo apaziguador porque não é uma contemplação desinteressada, e sim inserida no contexto das relações fenomênicas entre as coisas e os sujeitos coisificados. Em oposição a esta passividade, temos a relação de oposição mesmo dentro da anulação da consciência individual representada pelo sublime e que seria, conforme descrevemos anteriormente, prioridade do gênico, ou seja, o sublime.

O sentimento do sublime se origina aqui pela interiorização da insignificância de nosso próprio corpo frente a uma grandeza que por outro lado apenas reside em nossa representação e cujo portador somos enquanto sujeito cognoscente, e portanto aqui como em toda parte pelo contraste entre a insignificância e dependência de nosso eu como indivíduo, como fenômeno da vontade, frente à consciência de nós mesmos como sujeito puro do conhecimento ${ }^{23}$.

É através dessa possibilidade de consciência, no sentido de entendimento do papel do sujeito em relação à esta totalidade que lhe excede e tendo em vista quais as suas possibilidades de resistência, que o sublime pode ser entendido como contemplação estética não alienante, pois, ao contrário de identificar o sujeito ao objeto, ele permite sua plenificação através da consciência. No sublime opera-se uma relação dialética entre a percepção da insignificância do sujeito em relação ao todo e ao mesmo tempo o entendimento de que este todo é apenas representação do sujeito, de maneira que é nesse entendimento, nessa elevação da consciência a sujeito puro do conhecimento, que resida a possibilidade de resistência às tendências esmagadoras do universal e superação da dor oriunda do desejo, mormente dos desejos artificialmente despertados no sujeito.

\footnotetext{
23 SCHOPENHAUER, A. MRV III, § 39, p. 40. 


\section{Considerações finais}

Assim sendo, o que podemos perceber a partir da demonstração dos mecanismos esquematistas da Indústria Cultural, a partir dessa breve recapitulação, é que ela se apodera de todos os elementos que lhe estejam disponíveis, mesmo qeu estes sejam manifestações diretamente contrárias ao seu espírito manipulador, como a contemplação estética ou a tragicidade na arte. Dessa forma, podemos afirmar que não é a contemplação estética schopenhaueriana o que possibilita a alienação e a massificação, e sim o oposto; que a reificação de tantos aspectos da existência humana na modernidade e pós-modernidade não deixa incólume nem mesmo um mecanismo de superação da dor existencial de extrema erudição como a anulação da vontade através da contemplação metafísica da maneira como Schopenhauer a descreve no segundo ponto de vista sobre o mundo como representação em seu célebre livro.

Ao passo que em Schopenhauer a contemplação estética "carece de conteúdo", por isso a ênfase na música como forma de arte mais elevada, por não ser representativa, na indústria cultural, por outro lado, o conteúdo, que é subjacente à forma, é o aspecto mais importante: ainda que se afirme abertamente como mera distração, seu maior êxito e logro reside nas mensagens que passa. Dessa forma, a alienação se dá pelo apaziguamento alienante do belo e não pela provocação hostil do sublime.

Finalmente, uma questão quantitativa. De acordo com os argumentos de Schopenhauer, o homem que consegue adequada e mais duradouramente realizar a anulação da vontade através da contemplação estética é o gênio, o homem de exceção; apenas ele alcançaria, assim como os iluminados orientais, tornar-se o olho do mundo em completo desapego ao desejo individual consciente. O que percebemos no processo de banalização dessa possibilidade é o exercício de uma equação corriqueira: quanto maior a quantidade, menor a qualidade, ou seja, no momento em que essa possibilidade de elevação intelectual através da contemplação estética é estendida a um maior número de pessoas, ela começa a servir a interesses distintos daqueles com os quais foram originalmente considerados. Através do mesmo mecanismo, o da contemplação estética, da fuga de si como unidade subjetiva consciente, a indústria da cultura propiciou não a anulação da vontade e o alívio do sofrimento, e sim a transformação da condição ontológica humana de vontade de viver em vontade de consumo, Wille zum Kaufen. 


\section{Referências bibliográficas}

ADORNO, Theodor W. Minima Moralia. Tradução de Luiz Eduardo Bica, revisão de Guido de Almeida. São Paulo: Editora Ática, 1992.

BENJAMIN, Walter. A obra de arte na era de sua reprodutibilidade técnica, In:

Magia e Técnica, Arte e Política. 3. Ed. Tradução de Sérgio Paulo Rouanet e prefácio de Jeanne Marie Gagnebin. São Paulo: Brasiliense, 1987. Obras Escolhidas, Vol. I, p. 165196.

HORKHEIMER, Max. O pensamento de Schopenhauer em relação à ciência e à religião. Trad. Flamarion Caldeira Ramos. In: Cadernos de Filosofia Alemã XII. São Paulo: FFLCH-USP, 2008, p. 99 - 128. Disponível em: $<$ http://www.fflch.usp.br/df/site/publicacoes/filalema/filalema_12/FilosofiaAlema final. pdf $>$. Acessado em 28 nov. 2011.

HORKHEIMER, Max. Teoria Crítica I. São Paulo : Editora Perspectiva, 2004.

HORKHEIMER, Max. Teoria Tradicional e Teoria Crítica. In: Os Pensadores, Vol. XLVIII. São Paulo: Abril Cultural, 1980.

HORKHEIMER, Max; ADORNO, Theodor W. Dialética do Esclarecimento: Fragmentos Filosóficos. [Dialektik der Aufklärung: Philosophische Fragmente] Tradução de Guido Antonio de Almeida. Rio de Janeiro: Jorge Zahar Ed., 1985.

SCHOPENHAUER, Arthur. O mundo como vontade e representação, III Parte. In: Os Pensadores, Vol. XXXI. São Paulo: Editora Abril Cultural, 1974.

SCHOPENHAUER, Arthur. O mundo como vontade e representação. Tradução de M. F. Sá Correia. Rio de Janeiro: Contraponto, 2001. 